\title{
Isolated subpulmonary ring accompanied by infundibular located hypertrophia
}

\author{
Amine Tarmiz ${ }^{1}$, Hazem Alijla ${ }^{1}$, Imene Mgarrech ${ }^{1}$, Chokri Kortas ${ }^{1}$, Sofiane Jerbi ${ }^{1}$
}

1) Sahloul University Hospital, Department of Cardiovascular and Thoracic Surgery, MD, Sousse, Tunisia

\begin{abstract}
Congenital diseases causing obstruction of the right ventricular outflow tract (RVOT) are common, but the isolated subvalvular pulmonary stenosis is a very rare condition. Its diagnosis is obscure because of difficulty of comprehension of cardiac anatomy. We report a case of a 61-year-old female who presented for increasing shortness of breath on moderate exertion. Echocardiography showed an obstruction in the RVOT during systole by a subpulmonary fibrous ring with a mean gradient of $75 \mathrm{mmHg}$ through the ring. Under cardiopulmonary bypass, surgical resection was successfully performed. The patient continued to do well on follow-up in the out-patient clinic, 12 months postoperative.
\end{abstract}

Keywords: Subvalvular pulmonary stenosis, infundibular, hypertrophia, isolated subpulmonary ring.

Tarmiz A., Alijla H., Mgarrech I., Kortas C., Jerbi S. Isolated subpulmonary ring accompanied by infundibular located hypertrophia. EJCM 2017; 05 (1): 11-14. Doi: 10.15511/ejcm.17.00111. 


\section{Introduction}

Congenital diseases causing obstruction of the right ventricular outflow tract (RVOT) are common, but the isolated subvalvular pulmonary stenosis is a very rare condition. Its diagnosis is obscure because of difficulty of comprehension of cardiac anatomy. This case deals with clinical features and surgical findings on a lady with isolated subvalvular pulmonary ring.

\section{Case Report}

A 61-year-old lady was referred to our institution because of increasing dyspnea on effort NYHA III and two episodes of syncope. Her family history and past history were unremarkable. Examination revealed normal vital signs with systolic ejection murmur at the left sternal border. Her electrocardiogram showed right axis deviation with complete right bundle branch bloc. Chest X-ray revealed an important cardiomegalia without pulmonary congestion.

Transthoracic echocardiography (TTE) showed normal left ventricular ejection fraction, dilation of right heart cavities, and obstruction in the right ventricular outflow tract (RVOT) during systole, causing severe stenosis with a peak gradient of $90 \mathrm{mmHg}$. Right car-

\section{Figure 1. Right cardiac catheterization showed} a severe subvalvular pulmonary stenosis and integrity of the pulmonary leaflets

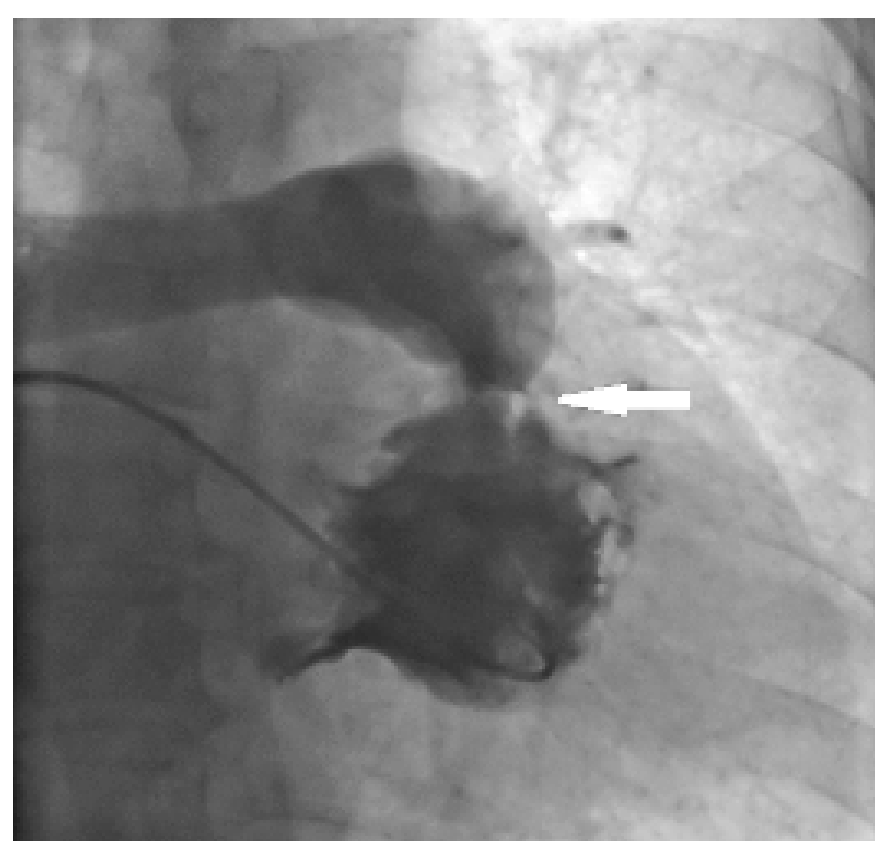

diac catheterization showed a severe subvalvular pulmonary stenosis and integrity of the pulmonary leaflets (Figure 1). There were no tricuspid regurgitation.

Transoesophageal echocardiography was performed preoperatively and confirmed these findings. The operation was performed through a median sternomomy. On bypass, the infunfibulum was opened longitudinally and an isolated fibrous ring $2 \mathrm{~cm}$ below the pulmonary valve was found (Figure 2). The pulmonary valve itself was normal. A complete resection of the ring was performed. The postoperative period was uneventful and the patient continued to do well 18 months after surgery.

\section{Discussion}

Subvalvular pulmonary stenosis commonly occurs as muscular hypertrophy associated with Tetralogy of Fallot or ventricular septal defect (VSD). ${ }^{[1]}$ Membranous subpulmonary stenosis is rare, and only few cases have been reported, mostly in association with other congenital defects like pulmonary valve stenosis and VSD. ${ }^{[2]}$ Isolated subpulmonary membranes are extremely rare. ${ }^{[3]}$ Kou-Gi Shyu ${ }^{[4]}$ reported 15 patients proved by surgery in a series of 3222 congenital heart diseases. The pathology of the fibrous ring can be related to tricuspid valve tissue or fibrous tags from the inferior vena cava or coronary sinus. ${ }^{[5]}$

The diagnosis of such a disease can be challenging, especially in adults, because of its rarity and the difficulty of assessing RVOT on TTE. Although echocardiography is the most commonly used non-invasive modality for diagnosing infundibular subpulmonary stenosis, but the detection rate by echocardiography is limited to approximately $70 \%$ of patients. ${ }^{[4]}$ More imaging using $3 \mathrm{D}$ echocardiography and cardiac $\mathrm{CT} / \mathrm{mag}$ netic resonance imaging (MRI) is highly recommended before surgical treatment. ${ }^{[6]}$

Cine MRI may be more accurate for the detection of infundibular subpulmonary stenosis, but it suffers the limitation that it only provides twodimensional visualization of the cardiac chambers and great vessels. Recently, free-breathing, whole-heart MRI has enabled three-dimensional visualization of not only the cardiac chambers and great vessels but also the coronary artery system with excellent spatial resolution. ${ }^{[7]}$ 
Treatment of infundibular stenosis is surgical when there is sufficient hemodynamic compromise. Surgical correction of uncomplicated isolated infundibular pulmonic stenosis under cardiopulmonary bypass is safe. ${ }^{[4]}$ In the series of Shyu K-G and al ${ }_{,}^{[4]}$ there was only one death with a surgical mortality of $6,7 \%$. All surviving patients had remained asymptomatic during the mean follow-up period of 35 months. Although patients can tolerate right ventricular hypertension for long periods of time, the optimal time for surgery is prior to the development of right ventricular failure.

\section{Conclusion}

We reported the case of an infundibular pulmonary stenosis associated with an isolated hypertrophy of the right ventricle in a 61-year-old lady.

Figure 2. On bypass, the infunfibulum was opened longitudinally and an isolated fibrous ring $2 \mathrm{~cm}$ below the pulmonary valve was found

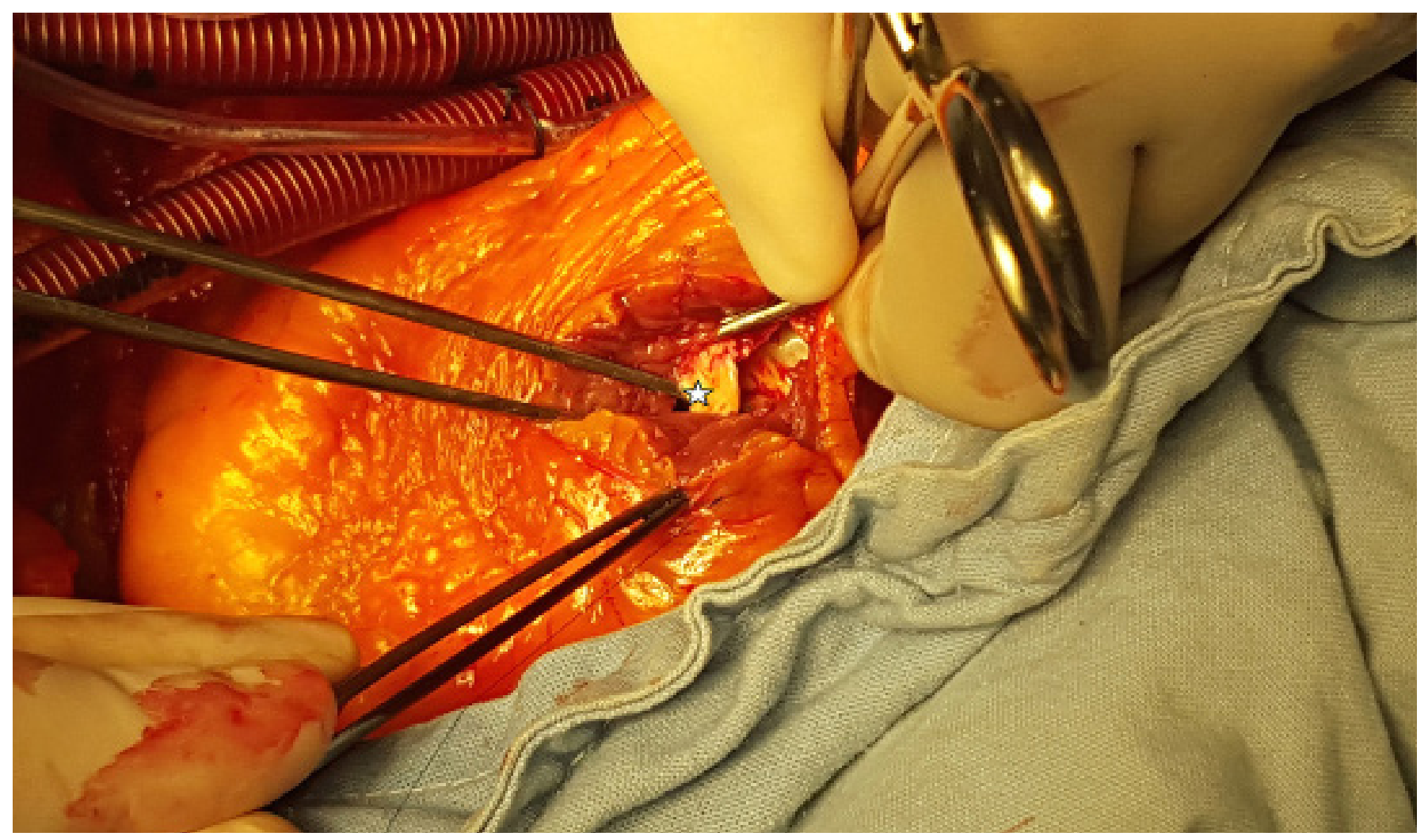




\section{References}

1. Anderson RH, Jacobs MJ. The anatomy of tetralogy of Fallot with pulmonary stenosis. Cardiol Young 2008;18:12-21

2. Raff GW, Gaynor JW, Weinberg PM, Spray TL, Gleason M. Membranous subpulmonic stenosis associated with VSD and AR. J Am Soc Echocardiogr 2000; $13: 58-60$

3. Tomar M, Radhakrishnan S, Shama R. Isolated subpulmonary membrane causing critical neonatal pulmonary stenosis with concordant atrioventricular and ventriculoarterial connections. Images Paediatr Cardiol 2009; $11: 5-9$

4. Shyu K-G, Tseng C-D, Chiu I-S, et al. Infundibular pulmonic stenosis with intact ventricular septum: a report of 15 surgically corrected patients. Int J Cardiol 1993;41:115-21

5. Bashore TM. Adult Congenital Heart Disease: right ventricular outflow tract lesions. Circulation 2007;14:1933-47

6. Yousif M, Elhassan NB, Ali SKM, Ahmed Y. Isolated subpulmonic fibrous ring, mirror-image dextrocardia and situs solitus in a young lady unreported and a near miss. Interact Cardiovasc Thorac Surg 2013;17:1043-4

7. Sato Y, Matsumoto N, Kunimasa T, et al. Whole-heart magnetic resonance imaging of isolated subpulmonary stenosis accompanied by hypertrophic cardiomyopathy. Int J Cardiol 2009;131:e73-e75

Received: 31/07/2016

Accepted: 17/02/2017

Published: 15/03/2017

Disclosure and conflicts of interest:

Conflicts of interest were not reported.

\section{Corresponding author:}

Dr. Amine Tarmiz

Mail: tarmizamine@yahoo.fr 